\title{
Analysis of the levels of Th9 cells and cytokines in the peripheral blood of mice with bronchial asthma
}

\author{
RUIFANG TONG ${ }^{1 *}$, LIPING XU $^{1 *}$, LIHONG LIANG $^{1}$, HAN HUANG $^{1}$, RUI WANG ${ }^{1}$ and YINGHUI ZHANG ${ }^{2}$ \\ ${ }^{1}$ Ward 1, Department of Respiration, Children's Hospital of Zhengzhou (Dongsan Street Hospital), Zhengdong, \\ Zhengzhou 450053; ${ }^{2}$ Children's Hospital of Zhengzhou, Zhengdong, Zhengzhou 450018, P.R. China
}

Received July 31, 2017; Accepted December 13, 2017

DOI: $10.3892 / \mathrm{etm} .2018 .5700$

\begin{abstract}
The purpose of the study was to detect the level of T-helper type 9 (Th9) cells and the cytokine interleukin-9 (IL-9) in peripheral blood of mice with bronchial asthma, and to explore the relationship between the expression of Th9 cells and the pathogenesis of asthma. Thirty female-specific pathogen-free (SPF) Bagg' albino (BALB)/c mice were selected and randomly divided into the control group $(n=15)$ and the bronchial observation group $(n=15)$. Mice in the bronchial observation group were treated with ovalbumin (OVA) for sensitization and induction of a mouse model of asthma. The airway reactivity of mice was measured by a mouse pulmonary function apparatus using the non-invasive pulmonary impedance method. The proportions of Th9 cells in peripheral blood of mice in the two groups were detected using flow cytometry. Digital polymerase chain reaction (dPCR), enzyme-linked immunosorbent assay (ELISA) and western blot analysis were applied to detect the levels of IL-9 messenger ribonucleic acid (mRNA) and proteins in peripheral blood and lung tissues of mice in the two groups, respectively. Compared with that in the control group, the expression level of Th9 cells in the peripheral blood of mice in the observation group was significantly elevated $(\mathrm{P}<0.05)$, the expression level of IL-9 proteins in the peripheral blood was significantly increased $(\mathrm{P}<0.05)$, and the levels of IL-9 mRNA and proteins in lung tissues were significantly increased $(\mathrm{P}<0.05)$. The results show that the levels of Th9 cells and their cytokine IL-9 in the peripheral blood of mice with bronchial asthma are significantly increased, suggesting that Th9 cells play important roles in the pathogenesis of asthma.
\end{abstract}

Correspondence to: Dr Yinghui Zhang, Children's Hospital of Zhengzhou, 33 Longhu-Waihuan-Dong Road, Zhengdong, Zhengzhou 450018, P.R. China

E-mail: yinghui_zhang123@163.com

*Contributed equally

Key words: bronchial asthma, Th9, IL-9

\section{Introduction}

Bronchial asthma is a type of disease with symptoms of bronchial hyper-responsiveness and airway obstruction. It is characterized by chronic airway inflammation and bronchial asthma. A relatively more unified view reveals that asthma is a development process, in which epithelial cells, fibroblasts, dendritic cells, eosinophils, mastocytes, $\mathrm{T}$ lymphocytes and other inflammatory cells interact with constituent cells of the airway, and the secreted inflammatory mediators participate in the development of asthma (1-3).

According to available data, the prevalence, mortality and treatment costs of asthma clearly show the rising trends globally. The prevalence of asthma is increased by approximately $50 \%$ every 10 years (4). Findings have shown that, the T-helper type 2 (Th2) subgroup in the cluster of differentiation 4 $(\mathrm{CD} 4)^{+} \mathrm{T}$ cells plays a key role in the occurrence of asthma, and it mediates the occurrence of II inflammatory responses by secreting a large number of cytokines, thus greatly promoting the occurrence of asthma $(5,6)$. Interleukin-9 (IL-9) has long been considered a Th2 cytokine, that plays an important role in the pathogenesis of asthma, parasitic infection in the body and the occurrence process of tuberculosis $(7,8)$. Newly identified Th9 cells are $\mathrm{CD}^{+} \mathrm{T}$ effector cells and are different from Th2, which are differentiated by the combined stimulation of transforming growth factor $\beta$ (TGF- $\beta$ ) and IL-4. They can secrete IL-9 and IL-10, albeit the former is the main type, and participate in asthma and parasitic infection-mediated immune responses such as Th2 cells (9-11).

In the present study, we established a mouse model of bronchial asthma to observe the roles of $\mathrm{Th} 9$ cells and their cytokine IL-9 in the pathogenesis of bronchial asthma.

\section{Materials and methods}

Reagents and instruments. Thirty female-specific pathogenfree (SPF) Bagg' albino (BALB)/c mice weighing 20.65 $\pm 2.35 \mathrm{~g}$ on average were included in the present study. Ovalbumin (OVA) was purchased from Sigma (St. Louis, MO, USA); aluminum hydroxide gel was purchased from Pierce (Rockford, IL, USA); IL-9 enzyme-linked immunosorbent assay (ELISA) kits were purchased from Boster Biological Technology Co., Ltd. (Wuhan, China); Roswell Park Memorial Institute (RPMI)-1640 medium was purchased from Gibco (Grand 
Island, NY, USA); fluorescein isothiocyanate (FITC)-labeled anti-human CD4 monoclonal antibodies, phycoerythrin (PE)-labeled anti-human IL-9 monoclonal antibodies and 2-SYBR ${ }^{\circledR}$ Green Real-time Polymerase Chain Reaction (PCR) Master Mixes were purchased from Vazyme Biotech Co., Ltd. (Nanjing, China). $\beta$-actin mouse monoclonal antibodies and goat anti-mouse horseradish peroxidase (HRP)-labeled secondary antibodies were purchased from Zhongshan Golden Bridge Biological Technology Co., Ltd. (Beijing, China); phorbol 12-myristate 13-acetate (PMA), ionomycin and monensin were purchased from Sigma. The microplate reader was purchased from Thermo Fisher Scientific, Inc. (Waltham, MA, USA) and the flow cytometer was purchased from Becton-Dickinson (Franklin Lakes, NJ, USA).

The present study was approved by the Ethics Committee of Children's Hospital of Zhengzhou (Dongsan Street Hospital).

Establishment of a mouse model of bronchial asthma. OVA was used for sensitization and induction of a mouse model of bronchial asthma. Fifteen mice in the observation group were intraperitoneally injected with $0.1 \mathrm{ml}$ saline solution containing $50 \mu \mathrm{g}$ OVA and $2 \mathrm{mg}$ aluminum hydroxide (at the concentration of $10 \%$ ) on days 0 and 14 . From day 21, the mice were placed in a closed box and atomized with $2.5 \%$ OVA solution for 7 days. In the control group, 15 mice were treated with sterile saline instead of OVA solution in the sensitization and induction phases. The usage and dosage were consistent with those in the observation group. The mice were sacrificed at the last $24 \mathrm{~h}$ after the atomization.

Detection of non-invasive pulmonary functions of mice. A Buxco non-invasive pulmonary function instrument (Buxco Respiratory Products, Data Sciences International) was connected, and the standard value was set. The airway responsiveness of mice in the two groups was detected. Then the two groups of mice were placed into a non-invasive pulmonary function instrument box. After the mice adapted to the environment for $5 \mathrm{~min}, 20 \mu \mathrm{l}$ mean corpuscular hemoglobin $(\mathrm{MCH})$ was added at concentrations of $0,6.25,12.50$ and $25.00 \mathrm{mg} / \mathrm{ml}$ for induction atomization, respectively. $\mathrm{MCH}$ at each concentration was used for atomization for $1 \mathrm{~min}$, and the results were recorded for $3 \mathrm{~min}$. At the end of the experiment, data and statistical results were output automatically. The ratio of specific airway resistance (sRaw) represented the level of airway responsiveness.

Detection of Th9 lymphocytes in peripheral blood of mice. Blood from abdominal aorta of mice in the two groups was extracted and mononuclear cells were isolated by lymphocyte separation medium. RMPI-1640 complete culture medium was used for cell suspension, and the cell concentration was adjusted to $2 \times 10^{6} / \mathrm{ml}$. The cells were then inoculated into 6 -well plates with $1 \mathrm{ml}$ per well. The medium was added mixed with PMA $(25 \mathrm{ng} / \mathrm{ml})$, ionomycin $(1 \mu \mathrm{g} / \mathrm{ml})$ and monensicillin $(1.7 \mu \mathrm{g} / \mathrm{ml})$, and cultured in an incubator with $5 \% \mathrm{CO}_{2}$ at $37^{\circ} \mathrm{C}$ for $6 \mathrm{~h}$. Cells were collected, placed in the flow tube (testing tube and control tube), and centrifuged for $5 \mathrm{~min}$ at rate of $2,600 \times \mathrm{g}$. The supernatant was then discarded, and $100 \mu \mathrm{l}$ phosphate-buffered saline (PBS) was added for resuspension. FITC-CD4 antibodies $(10 \mu \mathrm{l})$ were added in the testing and

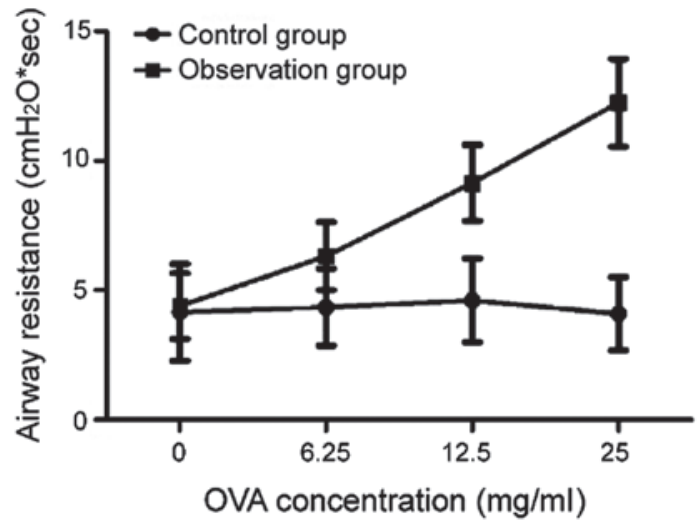

Figure 1. Comparison of the airway reactivity between the two groups. After the motivation of $\mathrm{MCH}$, the sRaw of mice in the observation group is significantly higher than that of the control group, and the difference is statistically significant $(\mathrm{P}<0.05)$. With the increase of $\mathrm{MCH}$ concentration, the sRaw of mice in the observation group increased gradually.

control tubes and incubated in the dark at room temperature for $15 \mathrm{~min}$. The tissues were washed twice with PBS, $100 \mu \mathrm{l}$ rupture agent was added, placed at room temperature in the dark for $10 \mathrm{~min}$, and centrifuged at the rate of 2,600 $\mathrm{x}$ g for 5 min. The supernatant was then discarded, $2 \mu 1$ PE-IL-9 antibodies were added to the testing tube, and $2 \mu \mathrm{l}$ of the same antibodies were added in the control tube for control. The antibodies were incubated at room temperature for $30 \mathrm{~min}$. After being washed twice, the cells were resuspended in $0.5 \mathrm{ml}$ PBS. The percentage of $\mathrm{CD} 4^{+} \mathrm{IL}-9^{+} \mathrm{T}$ cells in $\mathrm{CD} 4^{+} \mathrm{T}$ cells was detected.

Detection of the level of IL-9 messenger ribonucleic acid (mRNA) in lung tissues of mice. Lung tissues of mice in the two groups were placed in diethyl pyrocarbonate (DEPC)treated $1.5 \mathrm{ml}$ Eppendorf (EP) tubes, respectively. TRIzol (1 ml) (Invitrogen) was added, and an ultrasonic cell crusher was used for tissue homogenate. Chloroform (200 $\mu \mathrm{l})$ was added, thoroughly mixed with tissues and left to stand at room temperature for $3 \mathrm{~min}$. Tissues were then centrifuged at the rate of $9,100 \mathrm{x} \mathrm{g}$ at $4^{\circ} \mathrm{C}$ for $15 \mathrm{~min}$. The supernatant was transferred to another $1.5 \mathrm{ml} \mathrm{EP}$ tube, and tissues were added and mixed thoroughly with $500 \mu \mathrm{l}$ isopropyl alcohol and left to stand at room temperature for $10 \mathrm{~min}$. Subsequently the tissues were centrifuged at the rate of $5,800 \mathrm{x}$ g at $4^{\circ} \mathrm{C}$ for $5 \mathrm{~min}$. The supernatant was discarded, and $50 \mu \mathrm{l}$ ribonuclease (RNase)-free water-soluble liquid was added to obtain the total RNA. The concentration and optical densitity (OD)260/OD80 ratio were measured. The total RNA with (OD) 260/OD80 ratio between 1.8 and 2.0 were used for reverse transcription. A $20 \mu \mathrm{l}$ reverse transcription reaction system was established to obtain complementary deoxyribonucleic acid (cDNA), RNA was reversely transcribed into single-stranded cDNA according to the protocol of the reverse transcription kits (Takara Biomedical Technology Co., Ltd., Dalian, China). IL-9 primers used were: F: 5'-GTGACATACATCCTTGCCTC-3' and R: 5'-GTGGTACAACAGTTGGG-3'. Glyceraldehyde-3phosphate dehydrogenase (GAPDH) primers were: 5'-CTCTG CTCCTCCTGTTCGAC-3', and 5'-GCGCCCAATACGA CCAAATC-3'. A $20 \mu 1$ reverse transcription quantitative PCR 

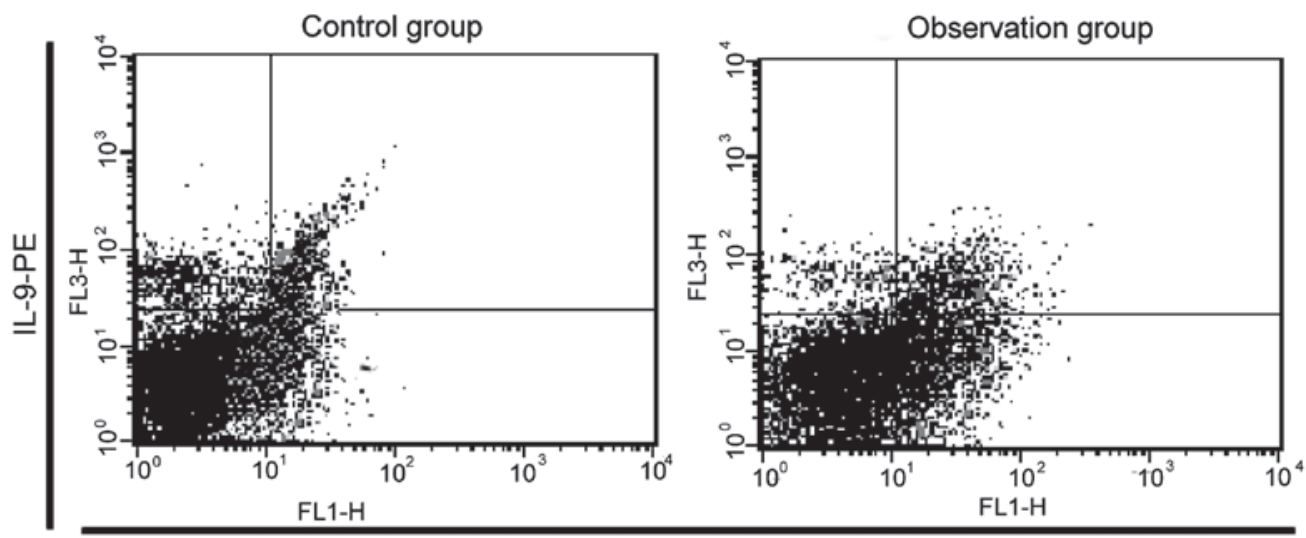

CD4-FITC

Figure 2. Comparison of Th9 cell subgroups of mice between the two groups. The proportion of Th9 cells in peripheral blood of mice in the control and observation groups was analyzed using flow cytometry. The proportion of Th9 cells in peripheral blood of mice in the observation group is significantly increased compared with that in the control group.

system (Vazyme Biotech Co., Ltd.) was established. The reaction conditions for the PCR were: denaturation at $95^{\circ} \mathrm{C}$ for $90 \mathrm{sec}$ annealing; at $95^{\circ} \mathrm{C}$ for $15 \mathrm{sec}$ extension; at $57^{\circ} \mathrm{C}$ for $20 \mathrm{sec}$ and further elongation; at $66^{\circ} \mathrm{C}$ for $30 \mathrm{sec}$; with a total of 35 cycles. Data were measured, and quantitative analysis was conducted ( $\Delta \Delta \mathrm{Cq}$ method).

Determination of the level of IL-9 proteins in peripheral blood and lung tissues of mice. The level of IL-9 in peripheral blood was detected using ELISA kits, in strict accordance with the protocol of the kit. IL-9 in lung tissues was analyzed by western blot analysis. Lung tissues $(5 \mathrm{mg})$ of mice in the two groups were taken, respectively, and placed in a homogenizer for full grinding. The cell suspension was transferred into a $1.5 \mathrm{ml} \mathrm{EP}$ tube, and tissues were centrifuged at the rate of $2,600 \times \mathrm{g}$ at $4^{\circ} \mathrm{C}$ for $10 \mathrm{~min}$. The supernatant was discarded, and the suspension was added with radioimmunoprecipitation assay (RIPA) lysate (Beyotime Biotechnology, Shanghai, China). The mixed liquor was vibrated for full mixing and then left to stand on ice for $30 \mathrm{~min}$ and tissues were centrifuged at the rate of $9,100 \times \mathrm{g}$ at $4^{\circ} \mathrm{C}$ for $10 \mathrm{~min}$. The bicinchoninic acid assay (BCA) kit (Beyotime Biotechnology) was used to detect the content of the proteins. After the sodium dodecyl sulfate polyacrylamide gel (10\%) electrophoresis (SDS-PAGE) was performed, the gel was transferred to polyvinylidene difluoride (PVDF) membranes. After specific blocking in bovine serum albumin (BSA) for $1 \mathrm{~h}$, the tissues were washed with phosphate-buffered saline supplemented with Tween-20 (PBST) 3 times for 5 min each time. Mouse anti-human IL-9 monoclonal antibodies (diluted at 1:500; cat. no. 564255) were incubated at $4^{\circ} \mathrm{C}$ for $12 \mathrm{~h}$, and tissues were washed with PBST 3 times for 5 min each time. Rabbit anti-mouse IgG monoclonal antibodies (1:1,000; cat. no. ZB-2305) were then incubated at room temperature for $1 \mathrm{~h}$, and the tissues were washed with PBST 3 times for 5 min each time. Membranes were coated with luminescent liquid for development with $\beta$-actin as the internal reference.

Statistical analysis. The experimental results were expressed as mean \pm standard deviation, and SPSS 19.0 software (SPSS, Inc., Chicago, IL, USA) was used for statistical analysis.

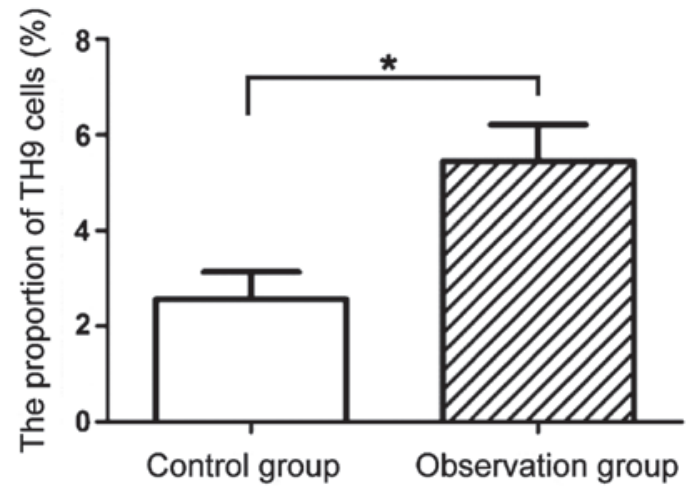

Figure 3. Comparison of Th9 cell subgroups between the observation and control groups. The histogram shows the proportion of TH9 cells in peripheral blood of mice in the control and observation groups. ${ }^{*} \mathrm{P}<0.05$.

Comparisons between groups were performed using LSD test. $\mathrm{P}<0.05$ was considered to indicate a statistically significant difference.

\section{Results}

Analysis of mouse behavioral manifestations and pulmonary functions. After the induction of OVA, varying degrees of symptoms emerged, such as forelimbs scratching the nose, dysphoria, lying prostrately without motion, depression, cyanosis, tachypnea, abdominal convulsions, urinary and fecal incontinence. After induction of $\mathrm{MCH}$, the sRaw of mice in the observation group was significantly higher than that in the control group, and the difference was statistically significant $(\mathrm{P}<0.05)$. With the increase of $\mathrm{MCH}$ concentration, the sRaw of mice in the observation group was increased gradually, indicating that mice in the observation group had bronchial hyper-responsiveness. The results of the analysis of mouse behavioral manifestations and pulmonary function verified that the mouse model was established successfully in the observation group (Fig. 1).

Comparison of Th9 cell subgroups of mice between the two groups. The results of flow cytometry are shown in Figs. 2 and 3. 


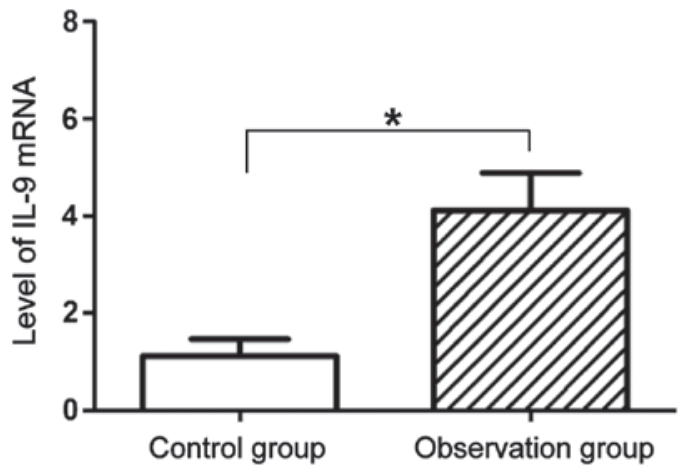

Figure 4. Comparison of the level of IL-9 mRNA of mice between the two groups. The expression level of IL-9 mRNA in lung tissues of mice in the control and observation groups was analyzed by qPCR. The expression level of IL-9 mRNA of mice in the observation group is significantly higher than that in the control group. ${ }^{*} \mathrm{P}<0.05$.

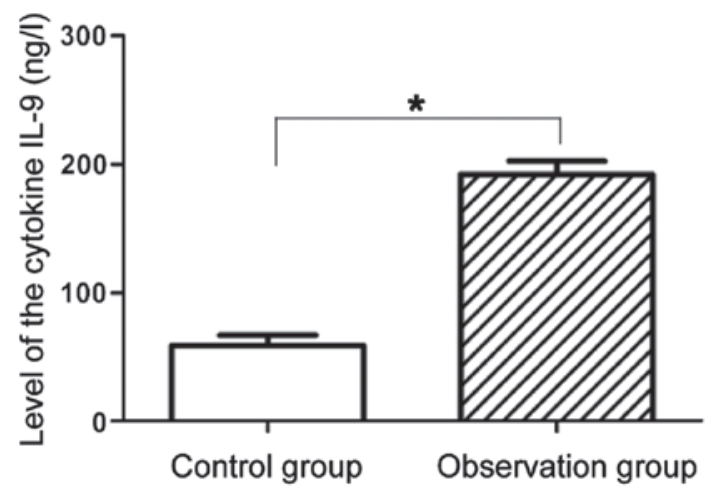

Figure 5. Comparison of the level of the cytokine IL-9 in peripheral blood between the two groups. The expression level of the cytokine IL-9 in peripheral blood of mice in the control and observation groups was analyzed by ELISA. The expression level in the observation group is significantly higher than that in the control group. ${ }^{*} \mathrm{P}<0.05$.

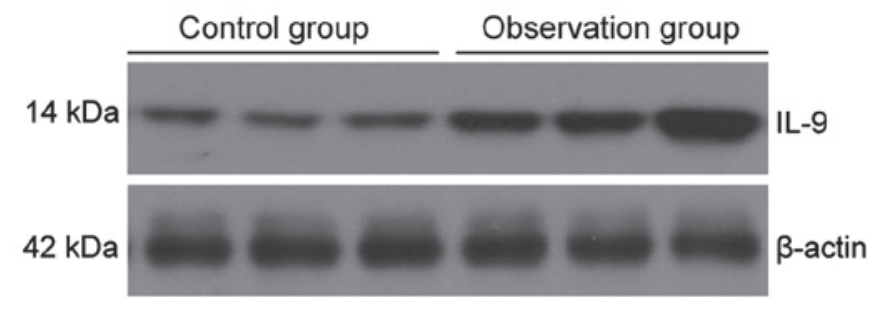

Figure 6. Comparison of the level of IL-9 proteins in lung tissues of mice between the two groups by western blot analysis. The level of IL-9 proteins in lung tissues of mice in the control and observation groups was analyzed by western blot analysis. The expression level in the observation group is significantly higher than that in the control group.

Compared with the proportion of Th9 cells in peripheral blood of mice in the control group (2.56 \pm 0.57$)$, that in the observation group $(5.45 \pm 0.76)$ was significantly increased $(\mathrm{P}<0.05)$.

Comparison of the level of IL-9 mRNA of mice between the two groups. The expression level of IL-9 mRNA in lung tissues was analyzed by qPCR. As shown in Fig. 4, the expression level of IL-9 mRNA in lung tissues of mice in the observation group $(4.12 \pm 0.76)$ was significantly higher than that in the control group (1.12 \pm 0.34$)$, and the difference was statistically significant $(\mathrm{P}<0.05)$.

Comparison of the level of IL-9 proteins in peripheral blood and lung tissues of mice between the two groups. Results of ELISA are shown in Fig. 5. Compared with the expression level of IL-9 proteins in peripheral blood of mice in the control group $59.43 \pm 7.91 \mathrm{ng} / \mathrm{l}$, that in the observation group $192.33 \pm 10.23 \mathrm{ng} / \mathrm{l}$ was significantly increased, and the difference was statistically significant $(\mathrm{P}<0.05)$. Results of western blot analysis of the level of IL-9 proteins in lung tissues indicated that the expression level of IL-9 proteins in lung tissues of mice in the observation group was significantly higher than that in the control group, and the difference was statistically significant $(\mathrm{P}<0.05)$ (Fig. 6).

\section{Discussion}

Bronchial asthma is one of the common chronic diseases of the respiratory system. There are approximately 230 million individuals with chronic asthma worldwide (12). The morbidity and mortality rates of asthma worldwide have gradually increased in recent years, which poses a great threat to human health (13). Virus infection, allergens and air pollution can induce the occurrence of acute asthma. Chronic non-specific airway inflammation and increased airway responsiveness are the most important features of asthma $(14,15)$. At present, the imbalance of the number and function of Th1/Th2 in $\mathrm{CD} 4^{+} \mathrm{T}$ lymphocyte subgroups is closely related to the pathogenesis of asthma. The incidence of asthma is mainly affected by Th2 cell-mediated immune responses (16). Previous findings showed that IL-9 plays an important role in asthma, parasitic infections and other Th2-related diseases (17). However, it has also been found that the function of IL-9 is not completely identical to that of other Th2-related cytokines. Therefore, $\mathrm{CD} 4^{+} \mathrm{Th}$ effector cells secreting IL-9 are a class of independent cell subgroups, namely Th9 cells $(9,18)$. Due to the important role of IL-9 in asthma, the action mechanism of Th9 cells, the main cells secreting IL-9, in bronchial asthma has drawn increasing attention.

In the present study, the mechanism of Th9 cells and the cytokine IL-9 in the study of pathogenesis of asthma was studied by establishing a mouse model of bronchial asthma. The flow cytometry analysis results of Th9 lymphocytes mouse in the model of bronchial asthma revealed that the level of Th9 cells in mice with asthma was significantly increased compared with that in normal mice, suggesting that Th9 cells play significant roles in the occurrence and development of asthma. IL-9 can act on a variety of inflammatory and tissue cells and play an important role in inflammation and allergic reactions, constituting a pathological factor of asthma (19). Researchers suggested that the level of IL-9 in patients with asthma can be used as one of the indicators for determining disease severity (20). In this study, both RT-PCR and western blot results indicated that the levels of IL-9 mRNA and proteins in lung tissues of mice with asthma were significantly higher than those in normal mice, which were consistent with those of Th9 cells.

In summary, Th9 cells, as a kind of important effector $\mathrm{T}$ cells, promote the occurrence and development of bronchial 
asthma together with their main cytokine IL-9, and may become an important indicator for determining the condition of asthma, thus providing a certain guidance for the clinical treatment of asthma.

\section{References}

1. Bui TT, Piao $\mathrm{CH}$, Song $\mathrm{CH}$, Shin HS and Chai $\mathrm{OH}$ : Bupleurum chinense extract ameliorates an OVA-induced murine allergic asthma through the reduction of the Th2 and Th17 cytokines production by inactivation of $\mathrm{NF \kappa B}$ pathway. Biomed Pharmacother 91: 1085-1095, 2017.

2. Junghans-Rutelonis AN, Tackett AP, Suorsa KI, Chaney JM and Mullins LL: Asthma-specific cognitions, self-focused attention, and fear of negative evaluation in adolescents and young adults diagnosed with childhood-onset asthma. Psychol Health Med 23: 69-81, 2018.

3. Nguyen DT, Kit BK, Brody D and Akinbami LJ: Prevalence of high fractional exhaled nitric oxide among US youth with asthma. Pediatr Pulmonol 52: 737-745, 2017.

4. Tsai MK, Lin YC, Huang MY, Lee MS, Kuo CH, Kuo PL, Lin $\mathrm{CH}$ and Hung $\mathrm{CH}$ : The effects of asthma medications on reactive oxygen species production in human monocytes. J Asthma: Jul 11, 2017 (Epub ahead of print).

5. Kaiser SV, Rodean J, Bekmezian A, Hall M, Shah SS, Mahant S, Parikh K, Morse R, Puls H and Cabana MD; Pediatric Research in Inpatient Settings (PRIS) Network: Rising utilization of inpatient pediatric asthma pathways. J Asthma: May 19, 2017 (Epub ahead of print).

6. Galli SJ: Mast cells and KIT as potential therapeutic targets in severe asthma. N Engl J Med 376: 1983-1984, 2017.

7. Fre ̌din MB, Puzyrev VP, Ogorodova LM, Saliukova OA, Kamaltynova EM, Kulmanakova IM and Petrovskaia IuA Analysis of the association between the T113M polymorphism of the human Il-9 gene and bronchial asthma. Genetika 36: 559-561, 2000 (In Russian)

8. Shao L, Cong Z, Li X, Zou H, Cao L and Guo Y: Changes in levels of IL-9, IL-17, IFN- $\gamma$, dendritic cell numbers and TLR expression in peripheral blood in asthmatic children with Mycoplasma pneumoniae infection. Int J Clin Exp Pathol 8: 5263-5272, 2015.

9. Li C, Jiang X, Luo M, Feng G, Sun Q and Chen Y: Mycobacterium vaccae nebulization can protect against asthma in $\mathrm{Balb} / \mathrm{c}$ mice by regulating Th9 expression. PLoS One 11: e0161164, 2016.
10. Koch S, Sopel N and Finotto S: Th9 and other IL-9-producing cells in allergic asthma. Semin Immunopathol 39: 55-68, 2017.

11. Wang JY, Zheng J, Xing HY and Jia XH: Determination of Th9 cells and IL-9 in children with Mycoplasma pneumoniae infection. Zhongguo Dang Dai Er Ke Za Zhi 17: 308-311, 2015 (In Chinese).

12. Poole JA: Asthma is a major noncommunicable disease affecting over 230 million people worldwide and represents the most common chronic disease among children. Int Immunopharmacol 23: 315, 2014.

13. Sposato B, Scalese M, Moschini G and Migliorini MG: Can we modulate asthma maintenance treatment level with disease seasonal variations? Eur Rev Med Pharmacol Sci 19: 942-949, 2015.

14. Chiu CD, Chen HJ, Saw HP, Yao NW, Yen HR and Kao CH: Asthma and early herniated intervertebral disc disease. Curr Med Res Opin 33: 2019-2025, 2017.

15. Jiang X, Chen Y, Feng G, Luo M, Sun Q and Li C: Th9 cells and related cytokines increase in the lung of mice with bronchial asthma. Xi Bao Yu Fen Zi Mian Yi Xue Za Zhi 31: 1067-1070, 2015 (In Chinese).

16. Song LJ, Wang ZX, Chi BR and Yang GZ: Regulatory effect of diammonium glycyrrhizinate on Th1/Th2 deviation in bronchial asthma: Experiment with rats. Zhonghua Yi Xue Za Zhi 87: 2865-2867, 2007 (In Chinese).

17. Gong F, Pan YH, Huang X, Zhu HY and Jiang DL: From bench to bedside: Therapeutic potential of interleukin-9 in the treatment of asthma. Exp Ther Med 13: 389-394, 2017.

18. Ying X, Su Z, Bie Q, Zhang P, Yang H, Wu Y, Xu Y, Wu J, Zhang M, Wang S, et al: Synergistically increased ILC2 and Th9 cells in lung tissue jointly promote the pathological process of asthma in mice. Mol Med Rep 13: 5230-5240, 2016.

19. Hoppenot D, Malakauskas K, Lavinskienė S, Bajoriūnienė I, Kalinauskaitè V and Sakalauskas R: Peripheral blood Th9 cells and eosinophil apoptosis in asthma patients. Medicina (Kaunas) 51: 10-17, 2015

20. Deng Y, Wang Z, Chang C, Lu L, Lau CS and Lu Q: Th9 cells and IL-9 in autoimmune disorders: Pathogenesis and therapeutic potentials. Hum Immunol 78: 120-128, 2017.

This work is licensed under a Creative Commons Attribution-NonCommercial-NoDerivatives 4.0 International (CC BY-NC-ND 4.0) License. 